\title{
Urban Tracer Dispersion and Infiltration into Buildings Over a 2-km Scale
}

\author{
J. C. Matthews ${ }^{1}$ (D) M. D. Wright ${ }^{1}$ - D. Martin ${ }^{1} \cdot$ A. Bacak ${ }^{2} \cdot$ M. Priestley ${ }^{2}$ T. J. Bannan ${ }^{2}$. \\ H. G. Silva ${ }^{3} \cdot$ M. Flynn ${ }^{2} \cdot$ C. J. Percival ${ }^{2,4}$. D. E. Shallcross $s^{1,5}$
}

Received: 4 October 2018 / Accepted: 2 December 2019 / Published online: 14 January 2020

(c) The Author(s) 2020

\begin{abstract}
Field experiments were undertaken in the summer of 2015 in Manchester, UK, to investigate the dispersion behaviour and infiltration into buildings of gas-phase pollutants over horizontal distances of 1-5 km. Inert cyclic perfluorocarbon tracers were released for $15 \mathrm{~min}$ at either one or three release points and samples taken in locations indoors and outdoors up to $2 \mathrm{~km}$ downwind. Background measurements of these cyclic perfluorocarbons range between 5.6 and 12.6 parts per quadrillion (ppq). On most occasions, tracer concentrations are higher on the sixth floor than at ground level. Tracer concentrations persist in the least well-ventilated rooms after concentrations return to background levels outdoors. The highest tracer concentrations, $329 \mathrm{ppq}$ above background, occur at dawn on 23 July from a sixth-floor sampling position during thermally stable conditions. At low wind speeds, tracer is detected upwind of the prevailing wind direction; on 24 July, tracer is detected to the north-west of the release point for north-north-east wind direction. A simple street network model does not predict tracer concentrations at low wind speeds over the $\mathrm{km}$ scales in this investigation due to tracer likely escaping the urban canopy. Predictions from a simple correlation model overestimate concentrations originating from distant sources, which is believed to be due to infiltration into buildings along the journey from source to receptor. A Gaussian plume model predicts the highest tracer concentrations for most receptor points on 23 July when the lowest Obukhov length of $-26 \mathrm{~m}$ was measured, agreeing with tracer measurements.
\end{abstract}

Keywords Air pollution · Dispersion · Perfluorocarbons · Pollutant infiltration · Tracer gases

Electronic supplementary material The online version of this article (https://doi.org/10.1007/s1054 6-019-00498-5) contains supplementary material, which is available to authorized users.

J. C. Matthews

j.c.matthews@bristol.ac.uk

Extended author information available on the last page of the article 


\section{Introduction}

\subsection{Rationale and Scope}

Flow through the complex geometries of cities plays an important role in determining air quality (Martin et al. 2008), with well-tested dispersion models required to understand many aspects of urban air pollution. Given the highly non-linear chemistry taking place in urban environments (Jenkin and Clemitshaw 2000), and the range of $\mathrm{NO}_{\mathrm{x}}$ levels that are encountered, the flow speed and the emissions affect oxidation rates significantly.

Several studies have investigated airflow (e.g. Martin et al. 2011a and references therein) through urban geometries, and derived parametrizations that describe downwind concentrations of pollutants for a given release rate, wind speed, and building geometry (Wood et al. 2009; Martin et al. 2010a). However, the movement of traffic along streets can act as both a source and cause of pollutant movement (Patra et al. 2008). Infiltration of material into buildings can alter tracer concentrations downwind (Martin et al. 2010b) with tracer campaigns showing tracers remaining within buildings long after they have cleared outside (Matthews et al. 2017). Infiltration into buildings may lead to wind-tunnel predictions overestimating concentrations as buildings are often considered impervious. Additionally, as the population spends significant portions of its life indoors, infiltration of pollutants into buildings has added significance with respect to human exposure. In the present study, we investigate dispersion over 'local' scales e.g. up to $2 \mathrm{~km}$ and in particular how tracers penetrate into the indoor environment.

A tracer campaign was undertaken in summer 2015 in the centre of Manchester, UK, to investigate the dispersion of pollutants over $2-\mathrm{km}$ scales in an urban environment. The aim was to identify processes that may cause the reduction of pollutant concentrations measured outdoors predicted by simple dispersion models, requiring samples to be taken indoors and outdoors at several heights and in a variety of sampling locations near a target building. Perfluorocarbon (PFC) tracers were used since they are inert, non-toxic, and able to be measured at small (parts per quadrillion, ppq) concentrations (Martin et al. 2011a). Many PFC exist in more than one isomer, with the same chemical formula but slightly different structure and therefore slightly different chemical properties, which are denoted by different prefixes. Three PFC tracers were used: perfluoromethylcyclohexane (PMCH; CAS-number: 355-05-2), a mixture of the cis-meta and trans-meta isomers of perfluoro2-4-dimethylcyclohexane (mPDMCH; 335-27-3), and perfluoro-2-methyl-3-ethylpentene (PMEP; 354-97-2). Background concentrations of perfluorodecalin (PFD; 306-94-5) were also measured, though the tracer was not used since the PFD tracer is often used in medical procedures, such as eye surgery, and the study location was close to the Manchester Royal Eye Hospital (Bourke and Cooling 1995).

\subsection{Background Perfluorocarbon Concentrations}

Few measurements of background PFC concentrations have been reported, though due to their use as an effective tracer gas and other applications (e.g. medical) background concentrations are increasing. Simmonds et al. (2002) measured PMCH and mPD$\mathrm{MCH}$ concentrations at Mace Head, Ireland in 2001; with values of $5.5( \pm 0.3) \mathrm{ppq}$ of PMCH, and $10.7( \pm 0.3) \mathrm{ppq}$ and $8.5( \pm 0.2) \mathrm{ppq}$ of the cis and trans isomers of the mPDMCH tracer respectively. Watson et al. (2007) measured a PMCH concentration 
of 8 ppq in 2007 and predicted an increase of 0.2 ppq per year. If we extrapolate this value we can tentatively estimate that the concentration of $\mathrm{PMCH}$ should have reached 9.6 ppq by 2015. Background measurements of PFD measured in 2003 and 2004 in Bristol, UK and Mace Head, Ireland reported background concentrations of $1.9 \mathrm{ppq}$ for cis-PFD and $1.7 \mathrm{ppq}$ for trans-PFD in Bristol and $1.6 \mathrm{ppq}$ for cis-PFD and $1.5 \mathrm{ppq}$ for trans-PFD at Mace Head, which could be expected to increase by a small amount in the intervening years (Shine et al. 2005).

\subsection{Flow Dispersion Models}

Plumes in urban dispersion are often partitioned into two regimes; a nearby regime, where the plume exists under the building height and a further regime where plume height is greater than the building height. Hanna et al. (1982) simplified the second regime using Monin-Obukhov similarity theory and described the ground-level maximum concentration $C_{\max }$ as a function of distance from the source $x$ as

$$
C_{\max } \propto x^{-n}
$$

where $n$ is between 1.5 and 1.75 . At $2 \mathrm{~km}$, the first regime may be more appropriate and Neophytou and Britter (2004) describe the concentration in their simple dispersion model as

$$
\frac{C_{\max } U h^{2}}{Q}=f\left(\frac{x}{h}\right)
$$

where $U$ is the wind speed at building height, $h$ is the average building height and $Q$ is the release rate of tracer. If building height is assumed to be large compared with the plume height the function on the right-hand side of Eq. 2 can be written as $K /(x / h)^{2}$ where $K$ is a dimensionless constant related to the shape and frontal areas of buildings, and therefore Eq. 2 simplifies to

$$
\frac{C_{\max } U}{Q}=\frac{K}{x^{2}}
$$

Through experiment, $K$ has been shown to be between 10 and 20 typically in UK and US cities (Martin et al. 2010a, b, 2011b).

Off-axis, the concentration in the plume falls away as a function of the turbulent properties of the atmosphere. Many dispersion models exist to quantify the horizontal and vertical dispersion of a plume in urban environments including Micro Swift Spray and QUIC (Hanna and Chang 2015) but a simple approximation can be made using a Gaussian plume model from a single point (Sutton 1953),

$$
C(x, y, z)=\frac{Q}{2 \pi \sigma_{y} \sigma_{z}}\left\{\exp \left[\frac{-\left(y^{2}\right)}{2 \sigma_{y}^{2}}\right]\right\}\left\{\exp \left[\frac{-(z-H)^{2}}{2 \sigma_{z}^{2}}\right]+\exp \left[\frac{-(z+H)^{2}}{2 \sigma_{z}^{2}}\right]\right\}
$$

where $C$ is the concentration at point $(x, y, z), \sigma$ is the standard deviation of the wind direction in that axis, and $H$ is the height of the plume release. 


\subsection{Street Network Analysis}

Petersson et al. (2010) attempted to fit a basic street-network model to their tracer release measurements whereby each intersection downwind of the tracer source was assumed to split the concentration into two components proportional to a constant, $R$ and $(1-R)$. They found a value of $R=0.17$ from the experimental results and calculated a value of 0.19 from the wind direction and geometry of the streets. They concluded that street channelling was of major importance in urban dispersion on the distance scales relevant to their investigation (less than $500 \mathrm{~m}$ ).

\section{Experimental Methodology}

\subsection{Site Description and Experimental Design}

Six tracer release experiments were undertaken between 15-24 July 2015 within an approximate 2-km radius of the Simon Building, Dover Street, University of Manchester $\left(53.4655^{\circ} \mathrm{N}, 2.2313^{\circ} \mathrm{E}\right)$. A small quantity of a PFC tracer was released from one or three release sites at emission rates between $0.01 \mathrm{mg} \mathrm{s}^{-1}$ and $2.7 \mathrm{mg} \mathrm{s}^{-1}$, according to the distance from the sampling points, and sampled into Tedlar bags at fixed monitoring sites. The air samples were then collected for analysis, and the concentration of tracer used to infer dispersion characteristics of the area under test. Each experiment was designed to provide an initial test of dispersion from varying distance under differing conditions. Before the tracer experiments were made, a background measurement was taken but PFD concentrations were elevated, which was assumed to be due to the usage of the PFD tracer within the eye hospital (Bourke and Cooling 1995). All samples were also analyzed for PFD concentration in case of the presence of other PFC tracers from the same source.

Figure 1 shows the release and sampling locations used, and Table 1 describes the sampling locations. Eleven samplers were used in each experiment and each was positioned in one of eighteen locations indicated in Fig. 1. Three sampling positions were in public parks (S16, S17, S18); three were outside on the University of Manchester campus (S2, S14, S15); seven were within the Simon Building of the University of Manchester, on various floors and with differing ventilation conditions (S1, S3, S4, S5, S7, S8, S10); four were outdoors on different floors of the same building (S2, S6, S9, $\mathrm{S} 11$ ); and one each on the ground and first floor outside the Williamson Building of the University of Manchester (S12, S13). Three of the samplers within the Simon Building were paired with a sampler outside to allow indoor /outdoor concentration comparisons. Figure 2 shows the location of three of these outdoor sampling locations.

In the first week, eleven sample locations were chosen centred on the Simon Building on Dover Street, University of Manchester. Three locations were chosen in or near the building, two inside-outside pairs, and a sampler outside at street level (Table 1). Two streetcanyon locations and two parks were also chosen, and outdoor samples were obtained by placing inlet lines through open windows in the Williamson Building across the street from the Simon Building. On 15 July, these positions were used to take background samples, on 16 July the PMCH tracer was released $1.7 \mathrm{~km}$ south-east of the Simon Building (R1, Fig. 1), and on 17 July the PMCH tracer was released $1.9 \mathrm{~km}$ to the south-west (R2, Fig. 1) 


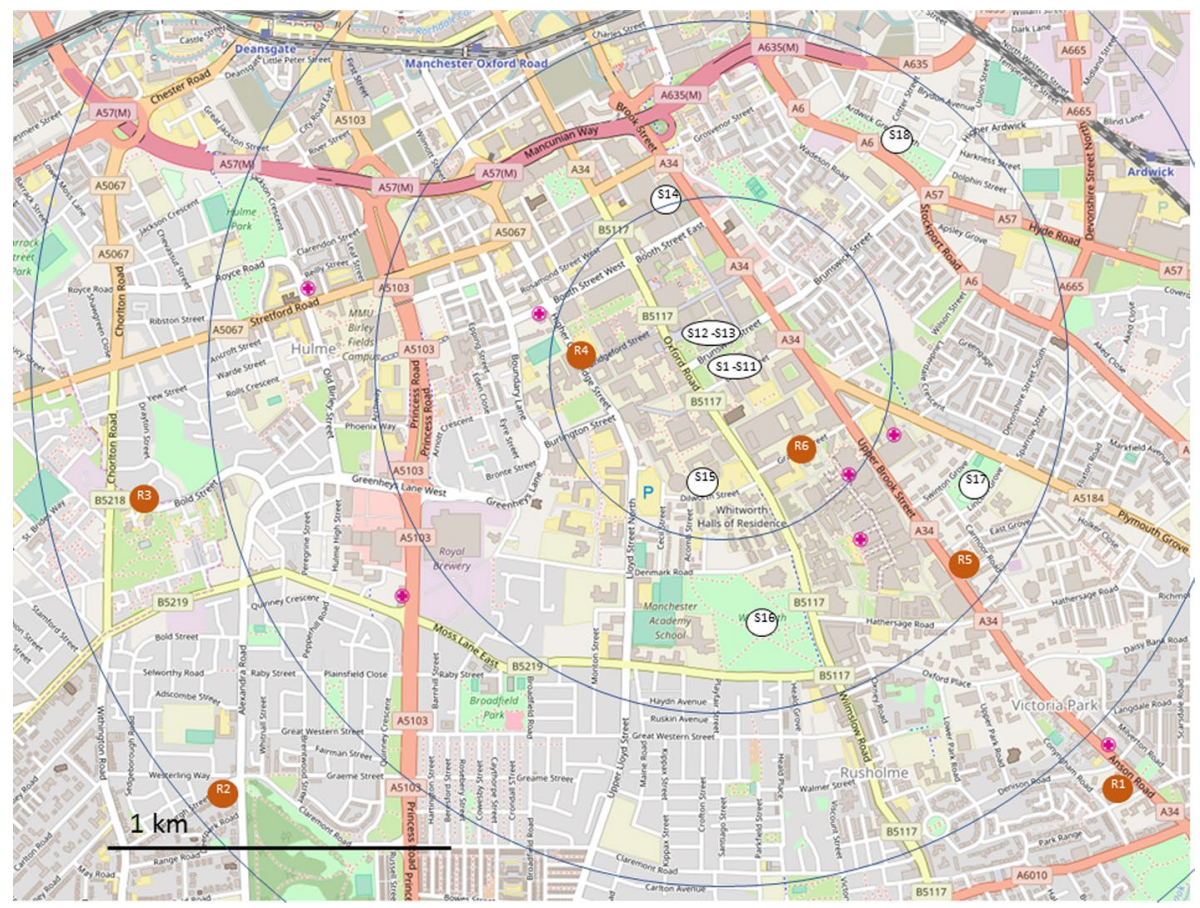

Fig. 1 Positions of the tracer releases (red; R1-R6) and samplers (white; 1-18). Circles are $500 \mathrm{~m}$ apart, centred on the Simon Building (Image (C) OpenStreetMap contributors, 23/06/2017)

On 21 July an experiment was designed to further investigate tracer ingress into a building (E3), and so sampling locations were changed to concentrate on the Simon Building. Sampling locations S1 to S11 were chosen, which included seven indoor and four outdoor locations, three of which were paired. Two additional samples after the first 30 min were taken in four indoor and one outdoor location. A tracer was released from the same position as $17 \mathrm{July}, 1.9 \mathrm{~km}$ to the south-west (R2).

Two experiments were conducted on 23 July, one at dawn (0700 British Summer Time, BST $=\mathrm{UTC}+1 \mathrm{~h}$; E4), and one at midday (1200 BST; E5). The sampling conditions remained the same as the measurements on $15 \mathrm{July}$, except for one park measurement that was moved from position S16 to position S18, so that the receptor was within the predicted plume from the release points. In these experiments, three chemicals were released simultaneously: the PMCH tracer was released $1.9 \mathrm{~km}$ to the south-west of the Simon Building (R2), the mPDMCH tracer was released $2.2 \mathrm{~km}$ west-south-west (R3), and the PMEP tracer released $400 \mathrm{~m}$ west (R4). The same release and sampling locations were used at dawn and noon.

The final experiment on 24 July (E6) released from three positions to the south-east of the Simon Building at distances of $1.9 \mathrm{~km}(\mathrm{R} 1, \mathrm{PMCH}), 0.9 \mathrm{~km}(\mathrm{R} 5, \mathrm{mPDMCH})$, and $0.3 \mathrm{~km}$ (R6, PMEP). Sampling positions were chosen at different heights in the Simon and Williamson Buildings. 


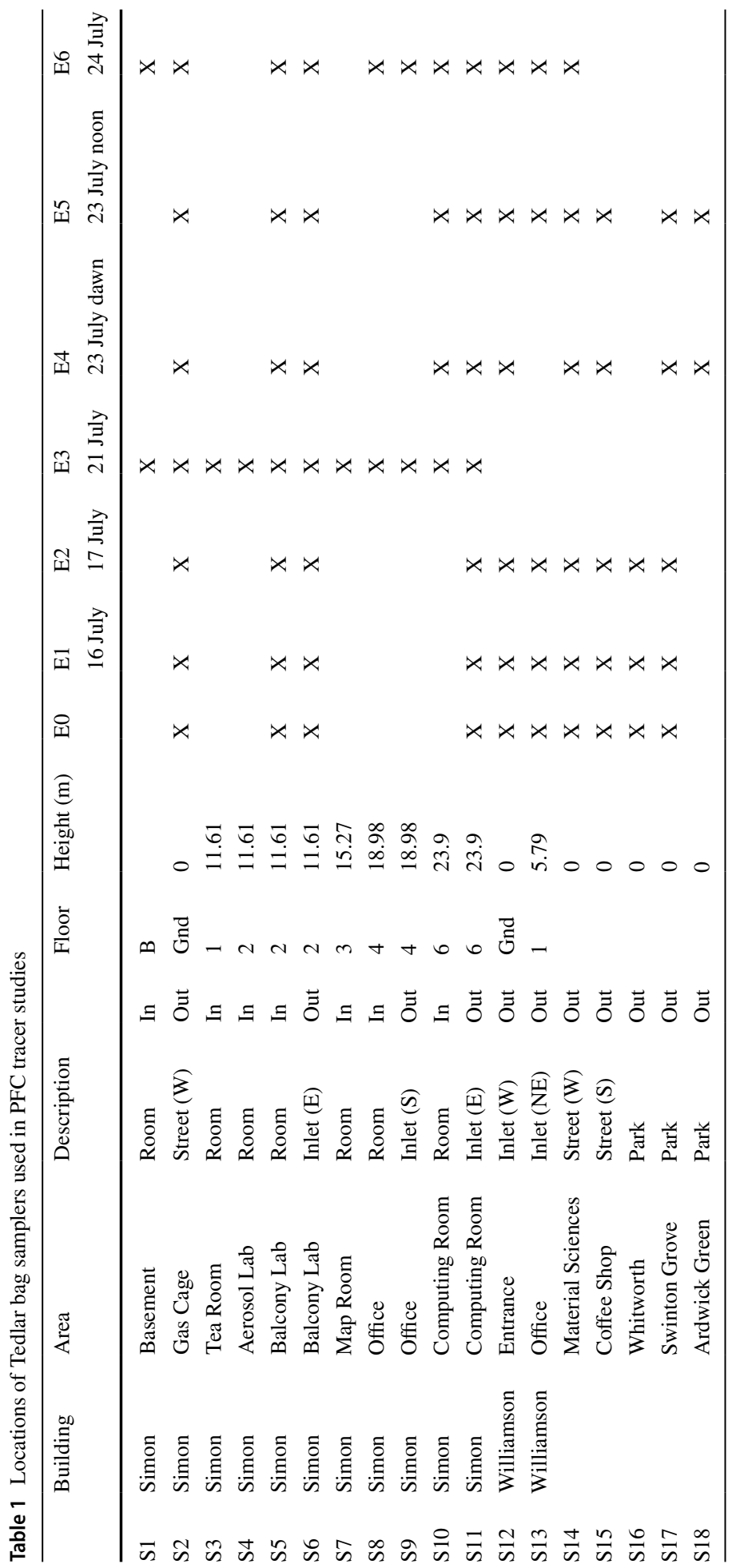




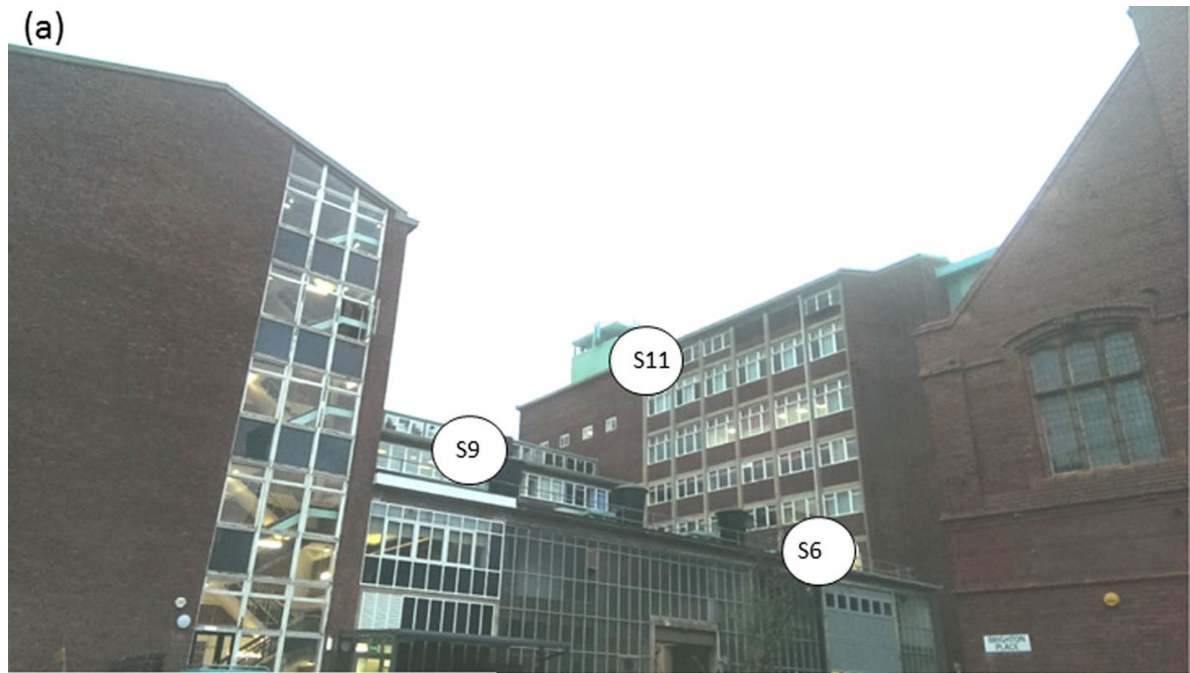

(b)

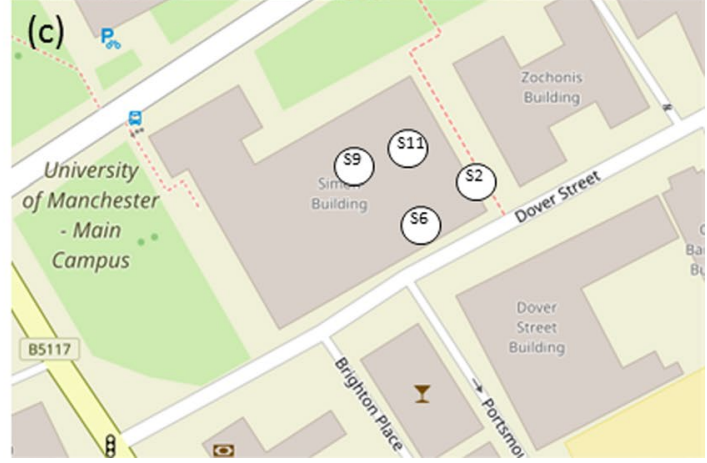

Fig. 2 Positions of the selected outdoor sampling locations within the Simon Building, University of Manchester; a photograph from Dover Street (image first published in Matthews et al. (2017)), b illustration of the positions looking from the south-west and $\mathbf{c}$ an overhead view, Image $(\subset)$ OpenStreetMap contributors, $23 / 06 / 2017$

\subsection{Perfluorocarbon Release}

The tracers used are cyclic-perfluorocycloalkanes, which are fluorinated cyclic alkanes chosen because they are inert and non-toxic. These were purchased as liquids (F2 Chemicals Ltd, Lancashire), the PMEP tracer was purified through multiple distillations, and these liquids were then used to prepare verified gas mixtures (BOC Specialty Gases, Linde Group, Immingham, UK) in air. Release gases were prepared at concentrations of 5643 ppm (PMCH), 1601 ppm (mPDMCH), and 1149 ppm (PMEP) in air with a certificated accuracy of $5 \%$. The release mixture of PMEP contained $4 \% \mathrm{mPDMCH}$.

Before each release, the PFC gas mixtures were decanted into $15 \mathrm{~L}$ silica-lined canisters (Restek Ltd., Bellefonte, Pennsylvania, USA), and during the experiment, release kits were transported to pre-agreed release positions (R1-R6; Fig. 1). The PFC tracer was released at $1-\mathrm{m}$ height, orientated to the forecast predominant wind direction for $15 \mathrm{~min}$ at a predetermined time indicated by synchronized clocks. A solenoid valve opened the cylinder and air was released at a rate of $1 \mathrm{~L} \mathrm{~min}^{-1}$. Pressure and temperature within the cylinders were 
both recorded during release using a Keller pressure transducer (Keller UK Ltd, Dorchester UK) and logged on a portable computer using CCS30 software (Keller UK Ltd, Dorchester UK). Flow rates of $1 \mathrm{~L} \mathrm{~min}^{-1}$ were controlled using a Flostat flow controller (Roxspur Measurement and Control Ltd, Hampshire, UK) which were verified using zero grade air and a flowmeter before experiments. The volume released was calculated later from the difference in pressure (adjusted for temperature) before and after release. Details of each experiment E1 to E6, including the amount of tracer released for each experiment, are listed in Table 2 .

A maximum concentration at the source receptors of $\approx 200$ ppq permits a good signalto-noise ratio for negative-ion chemical ionisation gas-chromatography mass-spectrometry (NICI-GC-MS) sampling analysis. Assuming a wind speed of $2 \mathrm{~m} \mathrm{~s}^{-1}$, Eq. 3 was used to estimate the required release rate, and with $K=10$, consistent with previous studies in UK cities (Martin et al. 2010a, b), this gave values of $118 \mathrm{ppq}$ to $470 \mathrm{ppq}$ between $1 \mathrm{~km}$ and $2 \mathrm{~km}$ for PMCH concentration; $267 \mathrm{ppq}$ to $30 \mathrm{ppq}$ for $\mathrm{mPDMCH}$ concentration between $0.5 \mathrm{~km}$ and $1.5 \mathrm{~km}$; and $383 \mathrm{ppq}$ to $43 \mathrm{ppq}$ for PMEP concentration between $0.5 \mathrm{~km}$ and $1.5 \mathrm{~km}$.

\subsection{Perfluorocarbon Sampling}

Bag samples were collected in custom-made $10 \mathrm{~L}$ Tedlar bags (SKC Ltd, Blandford Forum, UK) connected to an SKC Universal XR sample pump. Sampling was undertaken at $0.3 \mathrm{~L} \mathrm{~min}^{-1}$ for $30 \mathrm{~min}$, programmed to start at the same time as the tracer release, but finishing 15 min later so that the whole plume could be captured in the outdoor samples. Indoor samples were made contemporaneously with an outdoor sample in most cases to allow direct comparison of concentrations. On one day, three successive indoor samples were taken. Ventilation rates for the rooms were obtained in another study to enable interpretation of losses (Matthews et al 2017, Table 1, supplementary materials). However, direct comparison of concentrations indoors and outdoors are more directly relevant to human exposure. Where multiple samples were taken at the same location, an operator changed the bag within $1 \mathrm{~min}$ of the sample ending and programmed the subsequent sample. After the release, sample bags were collected and stored within black carrier bags (away from sunlight) and were kept separated from release equipment until analyzed to avoid contamination. Previous tests have shown that measured concentrations of PFC within Tedlar sample bags remain constant for up to 10 months (Simmonds et al. 2002), and all samples were analyzed within that time frame.

\subsection{Perfluorocarbon Analysis}

Bag samples were taken back to the laboratory at University of Bristol for analysis using NICI-GC-MS analysis. Samples were pre-concentrated using a custom-made adsorption-desorption system (Simmonds et al. 1995) and then injected into the GC-MS instrument system (GC model 6890, Hewlett Packard Ltd, USA; MS model 5973) fitted with an A12O3-PLOT-S column (Agilent Technologies UK Ltd, Cheshire, UK), selected to obtain good separation of PFC peaks (Ren et al. 2014). The mass spectrometer was run in selective ion-monitoring mode, and ions of mass 350 (PMCH), 400 (PDMCH), 438 (PMEP), and 462 (PFD) were recorded. The trans isomer of $\mathrm{mPDMCH}(\mathrm{mt}-\mathrm{PDMCH})$ co-elutes with the cis isomer of para-PDMCH (pc-PDMCH), while the cis isomer of $\mathrm{mPDMCH}$ 


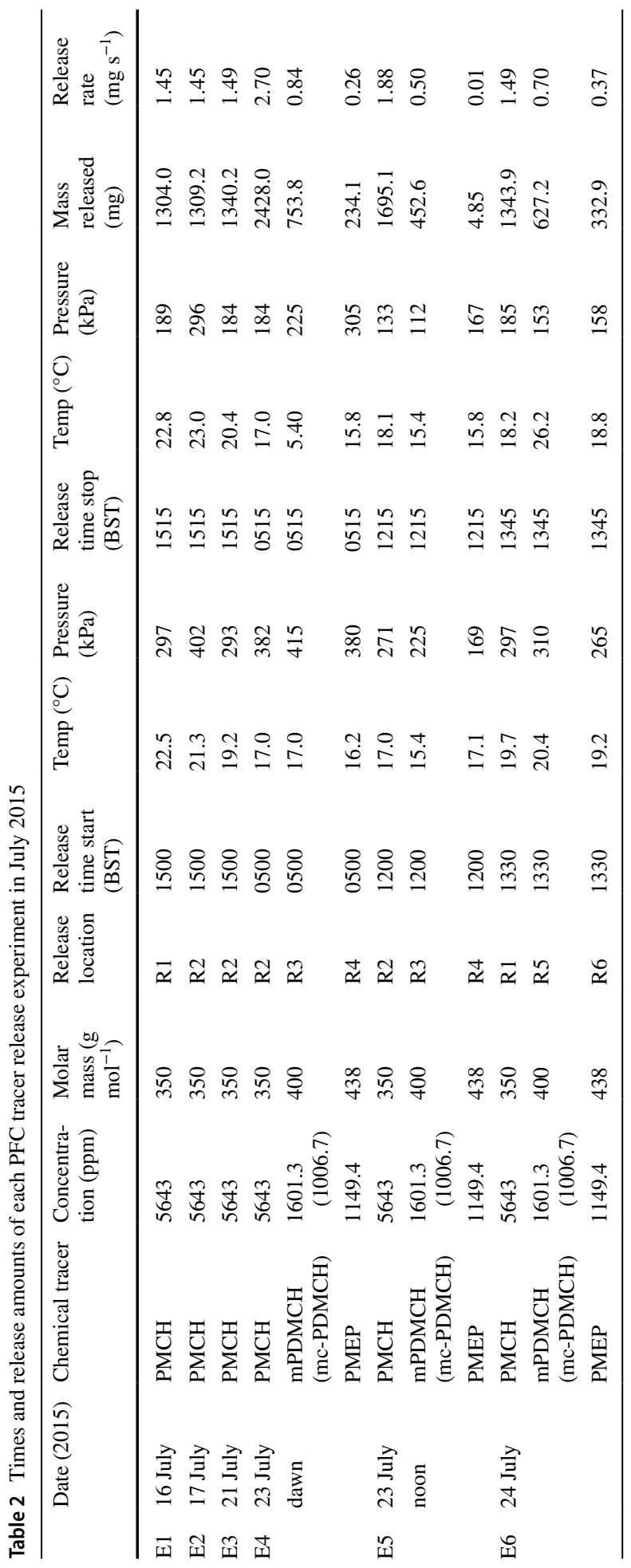


(mc-PDMCH) does not elute with another isomer under analysis, so the peak corresponding to mc-PDMCH was used in the analysis.

A volume of $3.5 \mathrm{~L}$ of the sample was trapped in the adsorption-desorption system, bookended with a $35-\mathrm{mL}$ sample of standard, and sample volumes were recorded using a timed flow through a mass-flow controller. Flow rates were verified using a rotameter before each measurement. The standard was prepared using chemicals supplied by F2 Chemicals Ltd (Lancashire, UK) and further purified at the University of Bristol. A BOC standard was prepared with quoted concentrations of $20 \mathrm{ppm}$ PMCH, 19.7 ppm PDMCH, 19.7 ppm PMEP, 20.4 ppm PFD, 5139 ppm CFC12 and 2411 ppm CFC11, with an accuracy of 5\%. The BOC standard was further diluted to 4 parts per trillion (ppt) by volume at the University of Bristol, and verified against CFC11 and CFC12 standards (error $<0.2 \%$ ), taking the mid-point of both values, using the GC-MS Medusa system (Miller et al. 2008), resulting in final concentrations of $4.08 \mathrm{ppt}(\mathrm{PMCH}), 4.01 \mathrm{ppt}(\mathrm{PDMCH}) \mathrm{comprising} 2.38 \mathrm{ppt} \mathrm{mc}-\mathrm{PDMCH}$ and $1.62 \mathrm{ppt} \mathrm{mt}-$ PDMCH, 4.02 ppt (PMEP), and 4.16 ppt (PFD). The PFD tracer eluted into two peaks, but as neither co-eluted with another compound in the standard, the sum of both peaks was used for analysis. The GC-MS response to standard concentration had a drift of less than $2 \%$ during the analysis, while the gas chromatograph signal-to-noise ratio indicated the limit of detection for the mass spectrometer, which was within acceptable tolerance due to the large $(3.5 \mathrm{~L})$ sample volume. The lowest was a signal-to-noise ratio of 12 for PMEP concentrations in the background measurements, which corresponded to less than $0.5 \mathrm{ppq}$ in a $3.5-\mathrm{L}$ sample, therefore we can place a limiting precision on all measurements of $1 \mathrm{ppq}$.

\subsection{Meteorology}

Meteorological conditions during all experiments were logged at the Whitworth Observatory at a rooftop position on the George Kenyon Building, a 50-m tower block which is the tallest in the vicinity, using a Gill Windmaster Pro ultrasonic anemometer recording three-dimensional velocity components at $10 \mathrm{~Hz}$ (Gill Instruments, Lymington, UK). The anemometer was placed on a stand $5 \mathrm{~m}$ high (3.6 m above the edge of the building), and $10 \mathrm{~m}$ from the edge of the roof, with these measurements supplemented by measurements from Manchester airport $\left(53.3537^{\circ} \mathrm{N}, 2.2750^{\circ} \mathrm{E}\right)$. Wind measurements at $1-\mathrm{s}$ intervals used a Gill Windsonic (15-17 July, 2015), then a Gill Windmaster (21-24 July 2015) on the second-floor balcony of the Simon Building, but the sheltered location of this instrument suggests that the wind speed and direction measured here may not be representative of broader conditions over the whole study area. In one release location per experiment, wind speed and direction were measured using a Gill Windsonic logged at $1-$ s intervals. The rooftop three-dimensional ultrasonic anemometer was used estimate the Obukhov length $(L)$ using

$$
L=-\frac{u_{*}^{3}}{\kappa \frac{g}{T} \overline{w^{\prime} T^{\prime}}} .
$$

where $u_{*}$ is the friction velocity, $\kappa$ is the von Kármán constant (taken to be 0.4 ), $g$ is the acceleration due to gravity $\left(9.8 \mathrm{~m} \mathrm{~s}^{-2}\right), T$ is the temperature, and $\overline{w^{\prime} T^{\prime}}$ is the kinematic surface heat flux (Foken 2006) . 


\section{Results and Discussion}

\subsection{Background Perfluorocarbon Concentrations}

Background samples were obtained before and after releases for nine release experiments throughout the study period, both inside and outside the Simon Building. Table 3 provides a summary of the background concentrations for the tracers used (PMCH, mc-PDMCH and PMEP); additionally, background concentrations of PFD were measured. For the set of background measurements taken on the morning of 15 July, highly elevated PFD concentrations were detected (mean concentration of $63.8 \mathrm{ppq}$, standard deviation $=10.9 \mathrm{ppq}$ ). Since it is possible that other PFC tracers could come from the same source as the PFD tracer, and as the source was not identified, these results were not included in the calculation of background concentrations.

A potential source of the elevated PFD concentrations is the Manchester Royal Eye Hospital, located south-east of the Simon Building, and west of Swinton Grove Park. The PFD tracer is often used in eye surgery (Bourke and Cooling 1995) and concentrations in the region of a few ppq could be detected at our sampling locations released from the hospital. It is also possible that the PFD mixtures used were not pure; background concentrations of $\mathrm{mPDMCH}$ and PMEP on 15 July were significantly above background. To increase confidence that contamination from PFC used in the eye hospital was not the source of elevated PFC concentrations during experiment days, the PFD concentration was analyzed in all samples, and if the total PFD concentration was consistently above measured background concentrations in any experiment, then the results were discarded.

The mean background concentrations (and standard deviation) for samples taken from 16 to 24 July, excluding the days where the PFD concentration was high, were PMCH: 11.4 (2.0) ppq; mc-PDMCH: 10.1 (0.5) ppq; PMEP: 5.6 (0.8) ppq; and PFD, which exists in two isomers, $2.5(0.3) \mathrm{ppq}$ and $2.3(0.3) \mathrm{ppq}$, total $4.7(0.6)$. These are slightly higher than background concentrations reported in the literature, in particular for PMCH concentration, for which Watson et al. (2007) predict values of $\approx 10 \mathrm{ppq}$, but are consistent with the slow rise of PFC concentration expected over time (Simmonds et al. 1995; Shine et al. 2005; Watson et al. 2007). The background concentrations have more spatial variation than might be expected, but as the elevated PFD concentrations measured on 15 July indicated, there may be local sources of trace levels of PFC in the study area.

During the experimental campaign, there were only two occasions when the PFD concentration was significantly outside of the background range (mean + two standard deviations). On the first occasion, the 16 July sample on the first floor of the Williamson

Table 3 Background concentrations of selected PFC tracers, averaged from nine samples taken between 15 and 24 July, five indoors and four outdoors

\begin{tabular}{lll}
\hline Chemical tracer & Mean (ppq) & $\begin{array}{l}\text { Standard } \\
\text { deviation } \\
(\mathrm{ppq})\end{array}$ \\
\hline PMCH & 11.4 & 2.0 \\
mc-PDMCH & 10.1 & 0.5 \\
mt,pc-PDMCH & 7.5 & 0.5 \\
PMEP & 5.6 & 0.8 \\
PFD1 & 2.5 & 0.3 \\
PFD2 & 2.3 & 0.3 \\
\hline
\end{tabular}


Building, a significant concentration of the PFD tracer, 1.5 ppq, above background, corresponded to a high $\mathrm{PMCH}$ concentration (35.9 ppq above background), although the mPDMCH concentration was not significantly above background. On the second occasion the PFD concentration was high (7.4 ppq above background) in the sample downwind of the Manchester Royal Eye Hospital at Swinton Grove Park (S17) at 0500 BST on 23 July, 2015, which indicates a likely, but small, contribution to PFC in the atmosphere from the eye hospital.

\subsection{Release Conditions}

Release masses were calculated from the measured change in pressure in the release canisters before and after release, adjusted for changes in temperature. Table 2 shows the mass released, and. further details of meteorological conditions during releases are included in supplementary materials where Table 2 shows the wind speed and direction at selected release sites over the 15 min of release, and the wind speed and direction from the Whitworth Observatory during the 30-min sampling period, and Figs. 1 to 6 show weather conditions for each release in more detail. Table 3 in Supplementary Materials lists the horizontal distances between the release positions and the sampling positions.

Atmospheric stability was estimated using the standard deviation of the vertical wind direction (Islitzer and Slade 1968) itself estimated using the method suggested by Yamartino (1984). These results are shown in Table 2 (Supplementary Materials). As might be expected in July with mostly clear skies, most release conditions are unstable, excluding the release at dawn made under highly stable conditions.

\subsection{Results of Tracer Experiments}

Table 4 in Supplementary Materials shows the increase in tracer concentrations (with background concentration subtracted from the sample measurement) for the first 30-min sample in each experiment. Background concentrations (one inside and one outside measurement) were obtained before the release, and the mid-point of the indoor and outdoor samples was subtracted from the measured values. On days where background concentrations were not measured, the nearest value in time was used. Results for each tracer were deemed significant if the measured concentration was greater than the mean background concentration paired to the sample concentration, plus two standard deviations across all background concentrations obtained for that tracer. (Results that were non-significant are listed as NS in the Table.) There is also a $1 \mathrm{ppq}$ analytical uncertainty and a 5\% systematic uncertainty in all measurements (including background concentrations) due to the quoted accuracy of the primary standard. Most measurements did not show PFD concentrations significantly above background (in this case, being two standard deviations of all background measurements, $1.2 \mathrm{ppq}$, above the measured background of that day) and therefore the assumption was made that there was no PFD tracer emission from the eye hospital on those days. The highest concentrations were measured when the tracer was released at sunrise; up to $330 \mathrm{ppq}$ of PMCH concentration above background was measured at the sixth floor of the Simon Building from a release $1.9 \mathrm{~km}$ away (R2). 


\subsection{Height Profile}

Throughout the experimental campaign, samples were taken outside the Simon Building at different heights. A sample was taken outside at street level (S2) on the north-east side of the building, on a balcony outside the second floor, facing south-west (S6), on two occasions from the window of an office on the fourth floor, facing south-east (S9), and outside on the sixth floor (S11) also facing south-west. Figure 2 shows the position of the samplers around the building. Figure 3 shows concentrations above background, adjusted by release concentration i.e. the concentration $\left(C, \mathrm{~kg} \mathrm{~m}^{-3}\right)$ of release mixture divided by release rate $\left(Q, \mathrm{~kg} \mathrm{~s}^{-1}\right)$, for each height on each day. All adjusted values are shown in Table 5, Supplementary Materials. The release distances were between 276 and 2889 m (Table 3, Supplementary Materials).

In most measurements, the tracer concentration was higher on the sixth floor of the Simon Building (S11) than at street level (S2). There were three measurements where the outdoor concentration at the sixth floor was not significantly above background. For two of these, the concentration at ground level was significantly higher than background. The ratio of concentrations at the sixth floor relative to the ground floor $\left(C_{S 11} / C_{S 2}\right)$ for each tracer release is shown in Fig. 4. For westerly winds, the Simon Building could conceivably shield the receptor at ground level from the tracer plume, but this effect is not discernible amongst other effects in these data as there is only one example of an easterly wind during the campaign to compare with the westerly winds.

This concentration ratio was compared with wind speed, wind direction, transit time (distance/wind speed) and to the ratio of building-height wind speed to release-height wind speed $\left(U_{H} / U_{Z}\right.$, a parameter that is a function of atmospheric stability). With the data available, no noticeable trend was evident. The largest difference between roof-level and ground-level concentrations occurred when the vertical wind speed was greatest and towards ground, as measured at roof height on 23 July. At this time the height of the measurements $(23.9 \mathrm{~m})$ approached the Obukhov length $(-30 \mathrm{~m})$, but this was also the case on two other measurements. An explanation could be that the plume is suppressed above the canopy, increasing concentrations, while other processes dominate within the streets. Wind measurements were not available at each sampling location but should be incorporated into any further studies.
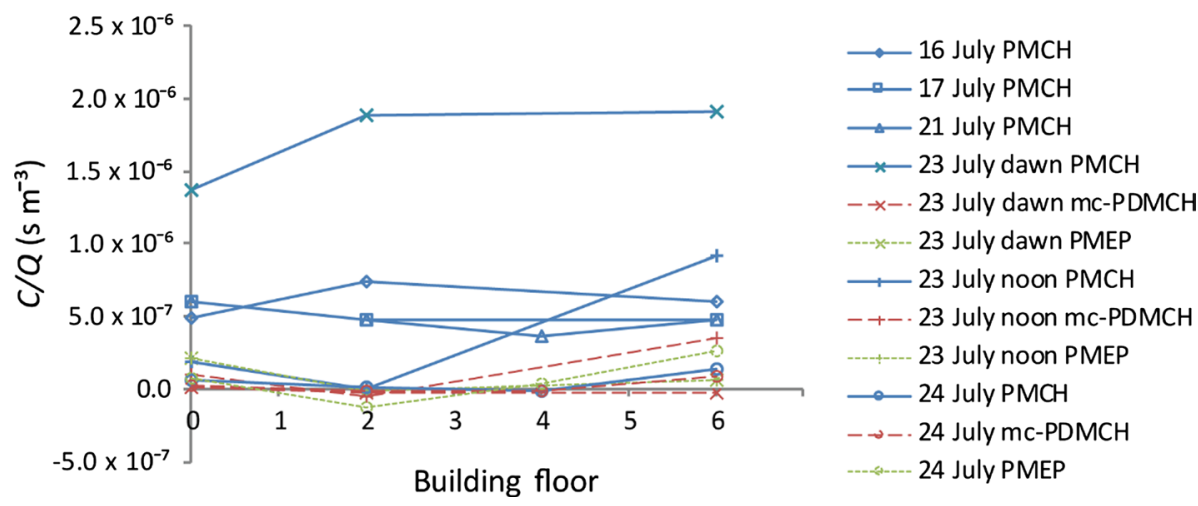

Fig. 3 Differences in tracer concentration above background divided by release rate $(C / Q)$ in the Simon Building at different heights, indicated by building floor 


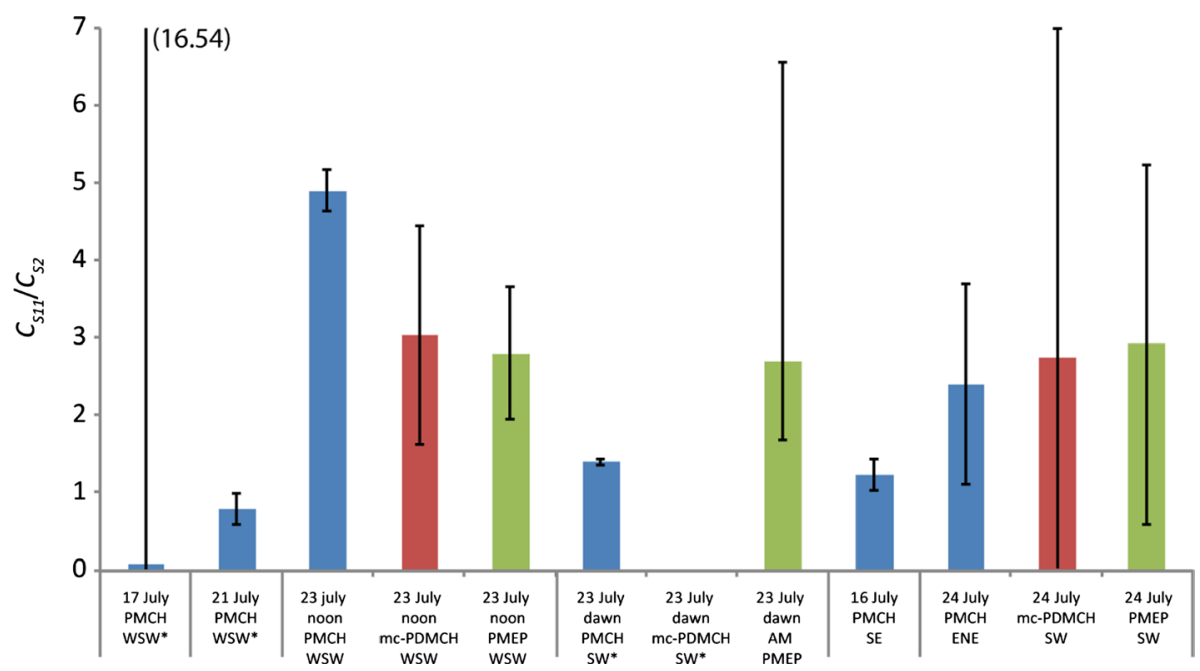

Fig. 4 The ratio of concentration above background outside on the sixth floor of the Simon Building to concentration at street level outside $\left(C_{S 11} / C_{S 2}\right)$, arranged by order of wind direction. Asterisks indicate measurements that were not significantly above background. Error bars represent the combination of analytical errors from the ground and sixth floor measurements

\subsection{Influx Indoors}

In three locations within the Simon Building (the second floor balcony lab, S5 and S6; the fourth floor office, S8 and S9; and the sixth floor computing room, S10 and S11), pairs of measurements were taken at the same time both inside and outside the building using a sampling line out of a window. The rooms were in use during many of the experiments and ventilation conditions (open windows, amount of times doors were opened) were not controlled, resulting in variable flows within the building.

Figure 5 shows the ratio of $\mathrm{PMCH}$ concentration indoors to concentration in samples taken outdoors at the same height (other tracers did not show significant results in either the indoor or outdoor tracer). There were 14 paired PMCH tracer measurements, seven paired mPCMCH tracer measurements and seven paired PMEP tracer measurements. Of these paired measurements, eleven outdoor concentrations were significantly above background. Of these, six also showed indoor tracer concentrations significantly above background, three on the second floor, one on the fourth floor and two on the sixth floor. There is considerable difference in the amount of tracer observed within the building for the different experiments, which cannot be explained with these experimental data.

At four indoor and one outdoor sampling locations, additional samples were obtained between 30 and $60 \mathrm{~min}$ and between 60 and $90 \mathrm{~min}$ after tracer release began, to examine whether the tracers remained in the building after the plume had passed outside. Figure 6 shows $C / Q$ for these five locations. The balcony laboratory indoor and outdoor samples have very similar concentrations, probably because the windows to the laboratory were fully open; the computing room was the largest room investigated, and the decay rate is the slowest; the aerosol laboratory was next door to the balcony laboratory, but windows were closed, so indoor concentration is lower and there is a slower tracer decay rate; the tea room was an internal room on the second floor with no windows, and we observed a lag in tracer reaching the room (concentration peaked in the 30-60-min sample). The finding 


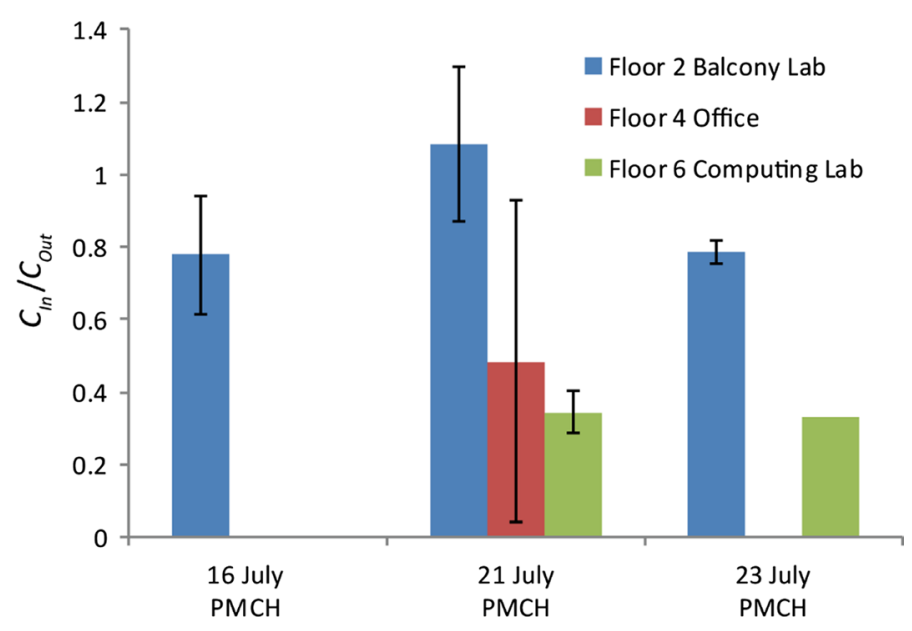

Fig. 5 The ratio of $\mathrm{PMCH}$ concentration above background measured inside compared to contemporaneous measurement outside $\left(C_{I n} / C_{\text {Out }}\right)$ on the same floor of the Simon Building

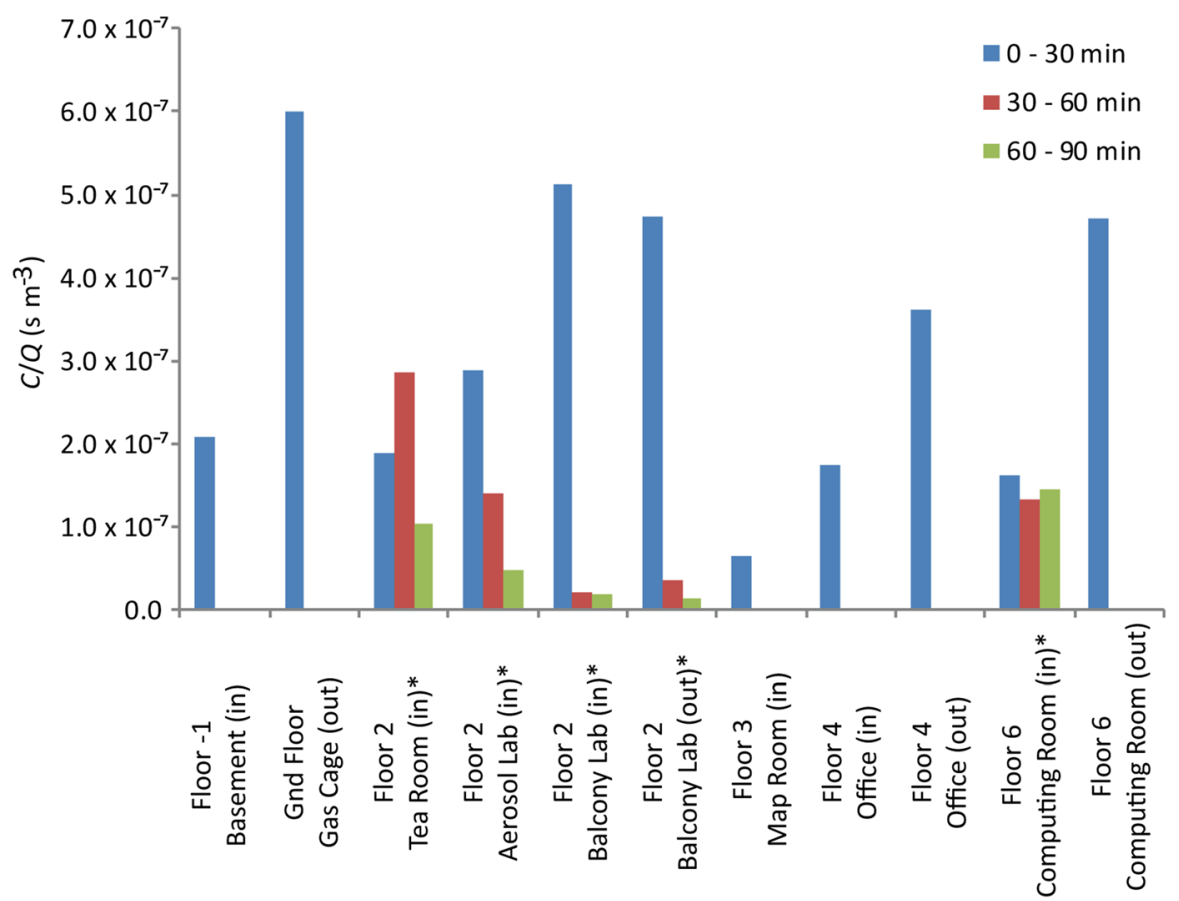

Fig. 6 Tracer concentration above background for each sampling location measured on 21 July 2015. Rooms marked with an asterisk had three subsequent 30-min samples, while those without had one 30-min sample 
that tracer concentrations remain relatively unchanged in the larger room is important and implies that building users may remain exposed to pollutants that have penetrated indoors well beyond the time when they have dispersed outside (Martin et al. 2010b).

Ventilation conditions within the Simon Building were investigated for a follow-up study on tracer infiltration (Matthews et al. 2017). The $\mathrm{CO}_{2}$ decay rate showed good correlation with that of PFC tracers, and rooms with the lowest ventilation rate had elevated tracer concentration for the longest. Ventilation rates for the rooms used in this study are given in Table 1, Supplementary Materials.

\subsection{Dawn Release}

On 23 July, two sets of three releases were made from the same release positions: R2, R3 and R4. One was at dawn (0500 BST) and the second at midday (1200 BST). The highest concentrations of tracer released $2 \mathrm{~km}$ away from the sampling locations were observed during the dawn experiment. Only one release at dawn was undertaken during this campaign, so no firm conclusions can be drawn, but this may be due to a stable overnight condition suppressing vertical diffusion. It is known that sunrise is associated with 'fumigation', a trapping of air near the ground as the dispersion characteristics change from a night-time inversion to daytime (Pasquill and Smith 1983), and this effect can be enhanced in cities due to the 'heat island' effect (Noto 1996). The wind data indicate that the atmosphere was unstable, even with a low level of sunlight, so some mixing should be expected. Further measurements at dawn are recommended to ascertain whether this is a consistent effect, when the change from stable overnight condition to fumigation begins to affect pollutant dispersion, and whether it increases the influx of tracer into buildings.

\subsection{Tracer Detection at Low Wind Speeds}

On 24 July, the wind direction changed during the morning from a forecast south-east wind direction to an east-north-east wind direction, therefore the receptor points at the Simon Building were not downwind of the release points as originally planned based on the forecast. Figure $6 c$, supplementary materials shows the wind rose of the release and $6 \mathrm{~d}$ the wind rose of the roof top measurement, both show little deviation from the east-north-east wind direction. (Further meteorological details can be found in Supplementary Materials.) Concentrations measured in this experiment were not much higher than the background with the exception of points S2, S8 and S11 where PMCH concentrations were 6 ppq, $8 \mathrm{ppq}$ and $13 \mathrm{ppq}$ above background respectively. The PMEP tracer, released from 400 $\mathrm{m}$ away at position R6, also showed a small but significant increase of nearly 2 ppq above background outside at ground level (S2) and outside on the sixth floor (S11), but was not significantly above background in position S8, where the PMCH tracer was elevated. The mc-PDMCH concentration was only elevated at the sixth floor (S11), the location which had the highest concentration of all three tracers. These results could be explained by turbulent effects or by traffic flow. The nearby A34 road is a busy traffic route that was close to all release points with traffic moving north-west and south-east. However, initial tracer movement due to entrainment by traffic would be at street level and highest concentrations were found at height. There are potential sources of PFC tracer, such as the Manchester Royal Eye Hospital, but PFD concentrations on this day were not above background, and background levels of the tracers within the study were not elevated before the release, so other sources would be an unlikely explanation. Building on previous numerical studies, 
Kastner-Klein et al. (2000) found that in a street canyon with moving traffic, the concentration within the canyon was reduced with increasing traffic speed, but increased with higher wind speed, supported by the higher concentrations at building roof height shown here.

The balance of turbulent effects on pollutant dispersion and the inertial effects of the stream of traffic is a topic that has entertained much interest (Jicha et al. 2000) and more field data would be worthwhile.

\subsection{Comparison with Street Network Model}

Figure 7 shows a simplified street network model of the University of Manchester area detailed in Fig. 1, with release points R4 and R6 indicated. The release point R4 was used in two release experiments, the dawn and noon releases undertaken on 23 July. The wind direction changed from south-west in the morning to west-south-west at noon between the two measurements, so the value of $R$, as discussed in Sect. 1.4, would also change, but it is possible to use the street network analysis to calculate an expected proportion of tracer at each downwind location. For example, the proportion of material expected at location S14 (Materials Science Stores) would be equivalent to

$$
P_{14}=3 R^{3}(1-R)^{3}+2 R^{2}(1-R)^{3}+R^{2}(1-R)^{2}+R(1-R)^{3}
$$

when all possible paths are included. For a south-westerly wind direction, $R=0.08$, therefore the proportion of tracer at position R4 that would reach position S14 is obtained by substituting $R=0.08$ into Eq. 6 , resulting in $P_{14}=0.08$. If the wind direction is west-southwest, the street network analysis predicts that no tracer would reach position $\mathrm{S} 14\left(P_{14}=0\right)$. As the other nearby sample points (S1-S13) are south of the release point, street network analysis as described by Petersson et al. (2010) would not predict significant amounts of tracer. However, as shown in Table 4, Supplementary Materials, we observed a significant amount of tracer at street level in locations S2 and S12 at noon.

Figure 7 shows a representation of the potential paths that tracer could take through the street channels; the major road is the Oxford Road, which has high traffic volume throughout most of the day. At low wind speeds, the wind direction shows some variability, with
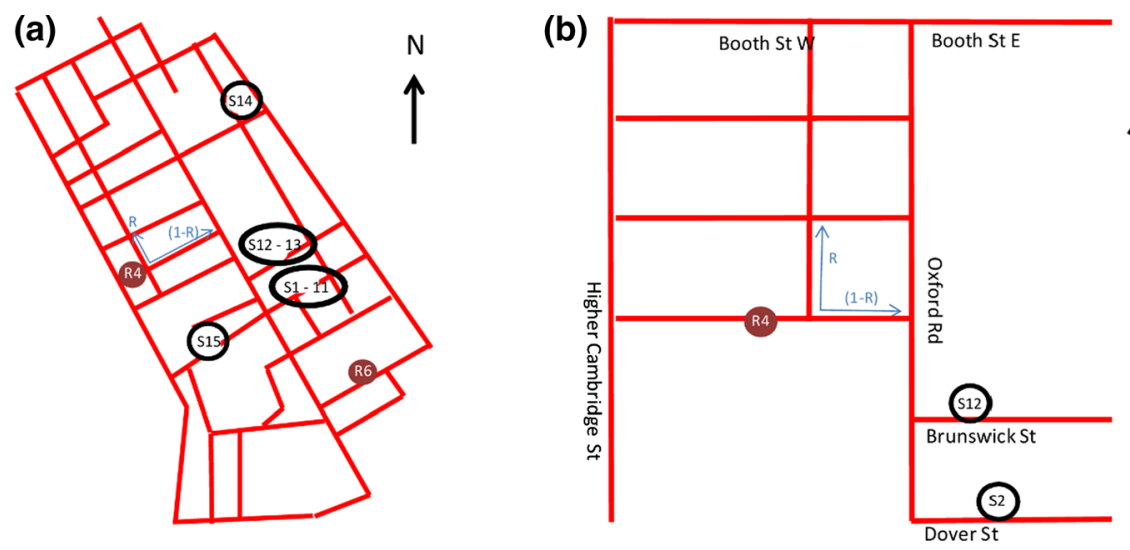

Fig. 7 a Street network for the area surrounding the University of Manchester, b simplified figure showing the street network near Dover Street and Oxford Road, Manchester 
northerly and southerly components measured as well as the west-south-west wind direction at ground level (Fig. 5c, supplementary materials). This will cause pollutants to be transported some distance contrary to the predominant wind direction. It has been shown in previous tracer experiments (Petersson 2009) that tracer can be measured in positions upwind from the release point due to traffic flow carrying airmasses in directions against the measured predominant wind direction. It is possible that some tracer was carried south along the Oxford Road, and which was then sampled in positions S2 and S12. Complex vortical flow in street canyons can influence the mean flow of pollutants in addition to traffic and variable wind direction, and additional transport of pollutants above roof level may occur due to chimney effects (Coceal et al. 2014).

This preliminary investigation at low wind speeds indicates that a simplified street network analysis may not be a good method for assessing tracer dispersion for the distances studied here without further refinement, and may be more suitable for the shorter scale work previously investigated. Once tracer has ascended above the street network it is free to flow and it is not surprising that over the longer distances sampled here, compared with the DAPPLE study (Shallcross et al. 2009; Wood et al. 2009; Martin et al. 2010a, b), that tracer has indeed escaped the urban canopy. A more detailed approach, such as that used by the SIRANE model (Ben Salem et al. 2015), may prove more effective at these scales.

\subsection{Comparison with a Simple Dispersion Model}

Estimates of maximum concentration at given distance were calculated for all measurement locations. Figure 8 shows that all measured concentrations were significantly above background, in comparison to the predictions of the simple dispersion model introduced in Sect. 1.4. Previous studies have shown that the simple dispersion model acts provides an

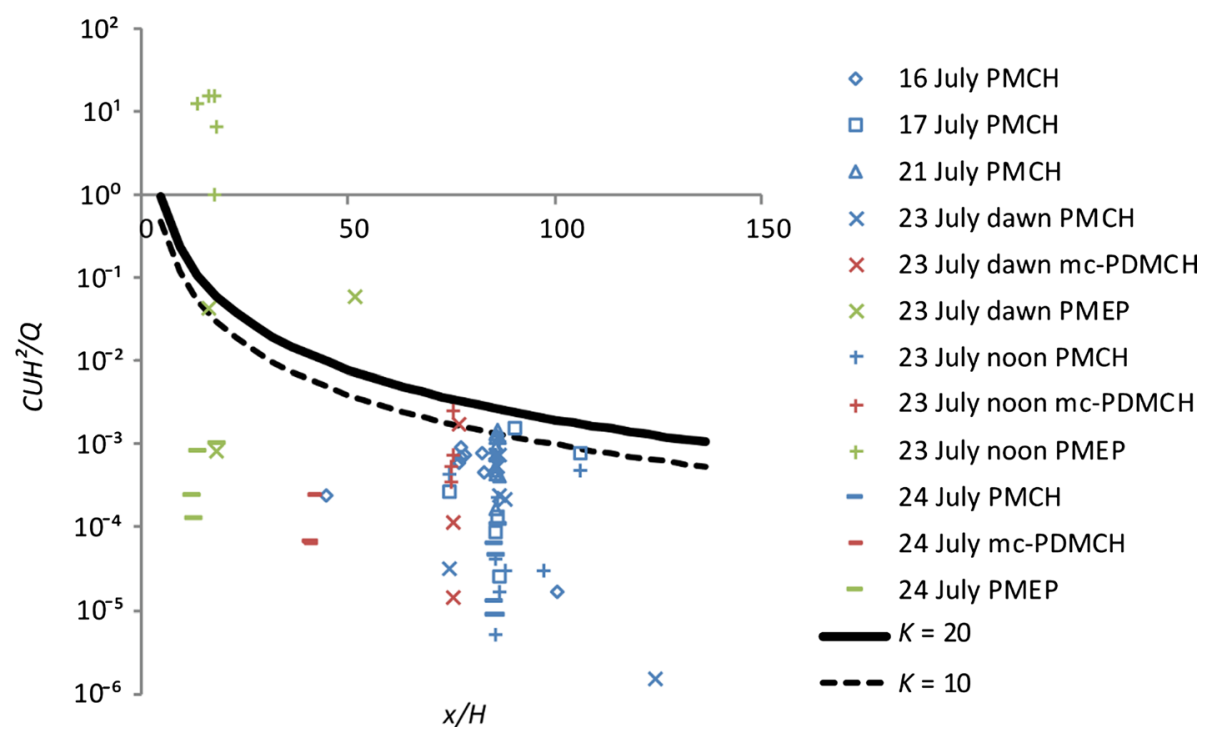

Fig. 8 Comparison with the simple dispersion model showing the maximum non-dimensional concentration against non-dimensional downwind distance from source. Dotted line, $K=20$, solid line $K=10$. Average building height assumed to be $H=40 \mathrm{~m}$ 
upper bound on tracer concentration at receptors (Martin et al. 2010b, 2011b). Receptors near to the release point have larger values due to street-channelling effects (Petersson et al. 2010).

The concentrations from the dawn PMEP tracer release, $\approx 400 \mathrm{~m}$ from the Simon Building, and the $\mathrm{PMCH}$ tracer release from $\approx 2 \mathrm{~km}$ distance, were higher than the limit indicated by the simple correlation model. The mc-PDMCH concentrations from the same day are lower, but the wind direction was such that the Simon Building was not downwind of the release point.

\subsection{Comparison with Gaussian Plume Model}

A simple Gaussian plume model was constructed using Eq. 4, with Pasquill stability classes estimated using Manchester airport METAR data (accessed from http://rp5.co.uk/ Weather_archive_in_Manchester_(airport),_UK,_METAR) to estimate values of $\sigma$ in Eq. 4 (Pasquill and Smith 1983). The calculated concentrations, normalized by the release rate $C / Q$, are given in Table 7, Supplementary Materials, while the measured results normalized by release rate are shown in Table 5, Supplementary Materials. Figure 9 shows the $\mathrm{PMCH}$ concentrations, normalized by the release rate, to indicate deviations from the model at the most distant release positions. The Gaussian model underestimates tracer concentration in many cases.

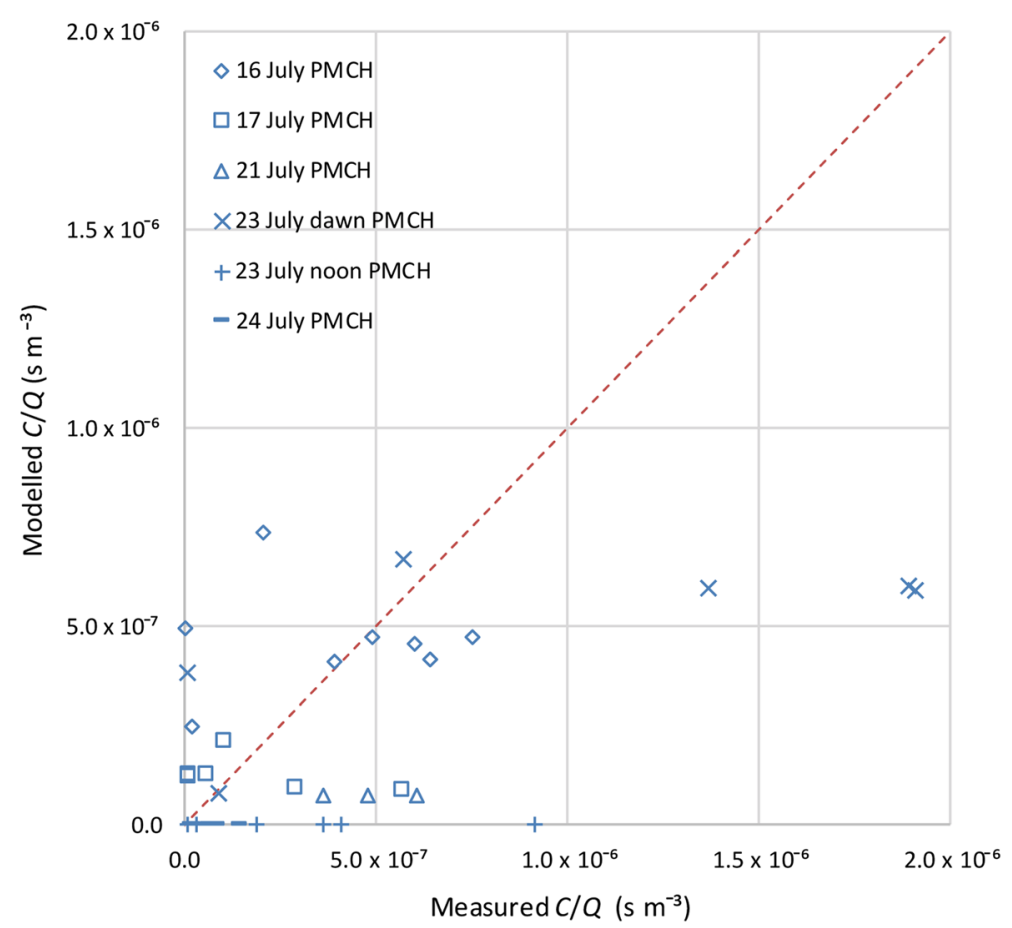

Fig. 9 Comparison of Gaussian plume level predictions of tracer concentration divided by release rate from Eq. 4, and measured concentration of tracer divided by release rate 
The highest measured and modelled concentrations, with the exception of the model result on 16 July, were observed on 23 July at dawn, where the highly stable atmosphere resulted in low $\sigma_{y}$ and $\sigma_{z}$ in Eq. 4, and hence a high $C$. The lowest Obukhov length was obtained at this time. Conversely, the most stable atmosphere and highest Obukhov length was obtained on 23 July, when the Gaussian plume model predicts low concentrations.

\section{Conclusions}

This campaign aimed to identify the dispersion behaviour and infiltration into buildings of gaseous material released in an urban environment. The most significant finding is the detection of elevated tracer levels within buildings that continue after the plume outside has passed. If infiltration into all nearby buildings of similar size and occupancy are considered, this could account for a significant redistribution of the plume concentration in time, leading to an overestimation of outdoor concentrations within dispersion models, as well as being an important consideration for human exposure to harmful gases.

Results showing elevated tracer concentration indoors $30 \mathrm{~min}$ to $1 \mathrm{~h}$ after tracer has returned to background levels outside is consistent with subsequent measurements undertaken in the same building (Matthews et al. 2017) and measurements taken in a separate study in London (Martin et al. 2010b).

A street channelling model was found to be insufficient to describe the transport of pollutants during low wind speed conditions, as material was found to travel contrary to prevailing wind directions. The simple correlation model tends to overestimate concentrations from sources released furthest away $(\approx 2 \mathrm{~km})$ which may be due to sampling away from the centre of the plume, but infiltration of tracer into buildings must also be considered.

Acknowledgements We thank NERC (NE/K01501X) and the Leverhulme Trust (RPG-2014-102) for funding for this work and Bristol ChemLabS for their support. We thank Dr. Anwar Khan for his advice during the planning of these studies.

Open Access This article is licensed under a Creative Commons Attribution 4.0 International License, which permits use, sharing, adaptation, distribution and reproduction in any medium or format, as long as you give appropriate credit to the original author(s) and the source, provide a link to the Creative Commons licence, and indicate if changes were made. The images or other third party material in this article are included in the article's Creative Commons licence, unless indicated otherwise in a credit line to the material. If material is not included in the article's Creative Commons licence and your intended use is not permitted by statutory regulation or exceeds the permitted use, you will need to obtain permission directly from the copyright holder. To view a copy of this licence, visit http://creativecommons.org/licenses/by/4.0/.

\section{References}

Ben Salem N, Garbero V, Salizzoni P, Lamaison G, Soulhac L (2015) Modelling pollutant dispersion in a street network. Boundary-Layer Meteorol 155(1):157-187

Bourke RD, Cooling RJ (1995) Perfluorocarbon heavy liquids. Aust Nz J Ophthalmol 23(3):165-171

Coceal O, Goulart EV, Branford S, Thomas TG, Belcher SE (2014) Flow structure and near-field dispersion in arrays of building-like obstacles. J Wind Eng Ind Aerodyn 125:52-68

Foken T (2006) 50 years of the Monin-Obukhov similarity theory. Boundary-Layer Meteorol 119(3):431-447

Hanna S, Chang J (2015) Skyscraper rooftop tracer concentration observations in Manhattan and comparisons with urban dispersion models. Atmos Environ 106:215-222

Hanna SR, Briggs GA, Hosker RP, United States. Department of Energy. Office of Energy Research. and United States. Department of Energy. Office of Health and Environmental Research (1982) 
Handbook on atmospheric diffusion: prepared for the Office of Health and Environmental Research, Office of Energy Research, U.S. Department of Energy. Technical Information Center, U.S. Dept. of Energy, Oak Ridge, TN

Islitzer NF, Slade D (1968) Diffusion and transport experiments. Environmental Science Services Administration, Idaho Falls, Idaho

Jenkin ME, Clemitshaw KC (2000) Ozone and other secondary photochemical pollutants: chemical processes governing their formation in the planetary boundary layer. Atmos Environ 34(16):2499-2527

Jicha M, Pospisil J, Katolicky J (2000) Dispersion of pollutants in street canyon under traffic induced flow and turbulence. Environ Monit Assess 65(1-2):343-351

Kastner-Klein P, Berkowicz R, Plate EJ (2000) Modelling of vehicle-induced turbulence in air pollution studies for streets. Int J Environ Pollut 14(1-6):496-507

Martin D, Price CS, White IR, Nickless G, Dobre A, Shallcross DE (2008) A study of pollutant concentration variability in an urban street under low wind speeds. Atmos Sci Lett 9(3):147-152

Martin D, Nickless G, Price CS, Britter RE, Neophytou MK, Cheng H, Robins AG, Dobre A, Belcher SE, Barlow JF, Tomlin AS, Smalley RJ, Tate JE, Colvile RN, Arnold SJ, Shallcross DE (2010a) Urban tracer dispersion experiment in London (DAPPLE) 2003: field study and comparison with empirical prediction. Atmos Sci Lett 11(4):241-248

Martin D, Price CS, White IR, Nickless G, Petersson KF, Britter RE, Robins AG, Belcher SE, Barlow JF, Neophytou M, Arnold SJ, Tomlin AS, Smalley RJ, Shallcross DE (2010b) Urban tracer dispersion experiments during the second DAPPLE field campaign in London 2004. Atmos Environ 44(25):3043-3052

Martin D, Petersson KF, Shallcross DE (2011a) The use of cyclic perfluoroalkanes and SF6 in atmospheric dispersion experiments. Q J R Meteorol Soc 137(661):2047-2063

Martin D, Petersson KF, White IR, Henshaw SJ, Nickless G, Lovelock A, Barlow JF, Dunbar T, Wood CR, Shallcross DE (2011b) Tracer concentration profiles measured in central London as part of the REPARTEE campaign. Atmos Chem Phys 11(1):227-239

Matthews JC, Bacak A, Khan MAH, Wright MD, Priestley M, Martin D, Percival CJ, Shallcross DE (2017) Urban pollutant transport and infiltration into buildings using perfluorocarbon tracers. Int J Environ Res Public Health 14(2):214

Miller BR, Weiss RF, Salameh PK, Tanhua T, Greally BR, Muhle J, Simmonds PG (2008) Medusa: a sample preconcentration and GC/MS detector system for in situ measurements of atmospheric trace halocarbons, hydrocarbons, and sulfur compounds. Anal Chem 80(5):1536-1545

Neophytou MK, Britter RE (2004) A simple correlation for pollution dispersion predicted in urban areas. DAPPLE note 1. www.dapple.org.uk. Accessed 9 Feb 2016

Noto K (1996) Dependence of heat island phenomena on stable stratification and heat quantity in a calm environment. Atmos Environ 30(3):475-485

Pasquill F, Smith FB (1983) Atmospheric diffusion. Ellis Horwood, Chichester

Patra A, Colvile R, Arnold S, Bowen E, Shallcross D, Martin D, Price C, Tate J, ApSimon H, Robins A (2008) On street observations of particulate matter movement and dispersion due to traffic on an urban road. Atmos Environ 42(17):3911-3926

Petersson FK, Martin D, White IR, Henshaw SJ, Nickless G, Longley I, Percival CJ, Gallagher M, Shallcross DE (2010) CityFlux perfluorocarbon tracer experiments. Atmos Chem Phys 10(13):5991-5997

Petersson KF (2009) An experimental investigation into dispersion mechanisms on urban and regional scales. Ph.D. thesis, University of Bristol

Ren Y, Schlager H, Martin D (2014) The application of TD/GC/NICI-MS with an Al2O3-PLOT-S column for the determination of perfluoroalkylcycloalkanes in the atmosphere. Chromatographia 77(3-4):309-316

Shallcross DE, Martin D, Price CS, Nickless G, White IR, Petersson F, Britter RE, Neophytou MK, Tate JE, Tomlin AS, Belcher SE, Barlow JF, Robins A (2009) Short-range urban dispersion experiments using fixed and moving sources. Atmos Sci Lett 10(2):59-65

Shine KP, Gohar LK, Hurley MD, Marston G, Martin D, Simmonds PG, Wallington TJ, Watkins M (2005) Perfluorodecalin: global warming potential and first detection in the atmosphere. Atmos Environ 39(9):1759-1763

Simmonds PG, Greally BR, Olivier S, Nickless G, Cooke KM, Dietz RN (2002) The background atmospheric concentrations of cyclic perfluorocarbon tracers determined by negative ion-chemical ionization mass spectrometry. Atmos Environ 36(13):2147-2156

Simmonds PG, Odoherty S, Nickless G, Sturrock GA, Swaby R, Knight P, Ricketts J, Woffendin G, Smith R (1995) Automated gas-chromatograph mass-spectrometer for routine atmospheric 
field-measurements of the cfc replacement compounds, the hydrofluorocarbons and hydrochlorofluorocarbons. Anal Chem 67(4):717-723

Sutton OG (1953) Micrometeorology: a study of physical processes in the lowest layers of the earth's atmosphere. McGraw-Hill Book Co., New York

Watson TB, Wilke R, Dietz RN, Heiser J, Kalb P (2007) The atmospheric background of perfluorocarbon compounds used as tracers. Environ Sci Technol 41(20):6909-6913

Wood CR, Arnold SJ, Balogun AA, Barlow JF, Belcher SE, Britter RE, Cheng H, Dobre A, Lingard JJN, Martin D, Neophytou MK, Petersson FK, Robins AG, Shallcross DE, Smalley RJ, Tate JE, Tomlin AS, White IR (2009) Dispersion experiments in central London the 2007 dapple project. Bull Am Meteorol Soc 90(7):955-970

Yamartino RJ (1984) A comparison of several single-pass estimators of the standard-deviation of wind direction. J Clim Appl Meteorol 23(9):1362-1366

Publisher's Note Springer Nature remains neutral with regard to jurisdictional claims in published maps and institutional affiliations.

\section{Affiliations}

J. C. Matthews ${ }^{1}$ D . M. D. Wright ${ }^{1}$ - D. Martin ${ }^{1}$ - A. Bacak ${ }^{2}$ - M. Priestley ${ }^{2}$ T. J. Bannan ${ }^{2}$. H. G. Silva ${ }^{3} \cdot$ M. Flynn ${ }^{2}$. C. J. Percival ${ }^{2,4}$ - D. E. Shallcross ${ }^{1,5}$

1 Atmospheric Chemistry Research Group, School of Chemistry, Cantock's Close, University of Bristol, Bristol BS8 1TS, UK

2 The Centre for Atmospheric Science, The School of Earth, Atmospheric and Environmental Sciences, The University of Manchester, Simon Building, Brunswick Street, Manchester M13 9PL, UK

3 Renewable Energies Chair, University of Évora, Casa Cordovil, Rua D. Augusto Eduardo Nunes, $\mathrm{n}^{\mathrm{o}}$ 7, 7000-651 Évora, Portugal

4 Present Address: NASA Jet Propulsion Laboratory, California Institute of Technology, Pasadena, CA 91109, USA

5 Department of Chemistry, University of the Western Cape, Bellville, South Africa 